\title{
La anunciadora azul de la muerte. De las creencias populares de los Andes Centrales
}

\author{
Mirosław Mąka \\ Instytut Etnologii i Antropologii Kulturowej, Uniwersytet Jagielloński \\ Elżbieta Jodłowska \\ Instytut Etnologii i Antropologii Kulturowej, Uniwersytet Jagielloński
}

En una de las pocas "lamentaciones - wanka" andinas del siglo XVII que han logrado salvarse, siguiendo el modelo del texto más antiguo de este tipo de obra en la lengua quechua, el Ataw Wallpap p'uchukakuyninpa wankan ${ }^{1}$ fechado a alrededores del año 1550 encontramos - aunque apareciendo en el margen de su tema principal - toda una serie de aportaciones a la etnografía y a la cultura espiritual de los pueblos andinos. Casi cada una de las frases de este poema incluye contenidos que parecen ser metáforas y adornos poéticos los cuales, sin embargo, representan para un etnólogo e investigador de las religiones, el valor de una fuente cuya forma se deja fácilmente descifrar y que hace referencia expresa a las áreas de las creencias tradicionales y a la mitología precolombina propia de esos pueblos. El poema al que estamos aludiendo, traducido por Jan Szemiński, ${ }^{2}$ constituye un ejemplo de la continuación de las formas literarias folclóricas cuyo inicio remontaría a la zona de Villcabamba de la mitad del siglo XVI revistiendo la forma de lamentación tras la muerte de Ataw Wallpa. Tanto aquel modelo inicial, como los poemas posteriores que en él se basaban iban representándose a lo largo de los siglos y hasta lo son en los tiempos

\footnotetext{
${ }^{1}$ Su texto completo junto con un comentario en: Inkowie 2015: 15-70.

2 Inkowie 2015: 71-79.
} 
contemporáneos, básicamente por los grupos teatrales ambulantes, durante las fiestas y ferias en pueblos pequeños dispersos a lo largo y ancho de los inmensos terrenos de los Andes y los del Altiplano. Transmitidas de generación en generación, copias de estos textos las encontraron los etnógrafos en muchos sitios yendo desde Cajamarca en el Norte del Perú hasta el Potosí boliviano. Las Wankas se han arraigado profundamente en la cultura plebeya de los Andes volviéndose portadores de la historia mítica del Perú en un momento transcendente de su historia: la llegada de los españoles y el inicio de la Conquista. Jugaban y, en gran medida siguen jugando hasta hoy día, el papel de un mensaje lúdico cargado de emociones que iba difundiendo la visión popular de aquellos sucesos y al mismo tiempo haciendo que se vuelvan parte de un sistema de creencias míticas más amplio y exponiendo de forma particular el tema milenario que presagiaba el retorno del Inca y el renacimiento de Tawantin Suyu. ${ }^{3}$ Este sentido fundamental y constitutivo de las lamentaciones wanka ha sido ya objeto de análisis profundos. Los detalles del contenido y de la construcción de estas obras atrapan la atención de sus investigadores por lo complejo que son sus contextos, lo plural que son las maneras en las que pueden leerse y por la irrepetible sinergia del contenido verbal y del simbolismo visual que presentan, volviendo una unidad la tragedia y lo cómico de su representación lúdica. ${ }^{4}$

Por entre la riqueza de los detalles etnográficos que contiene dicha lamentación encontramos una aportación importante y cronológicamente temprana al tema de nuestra investigación. Un poeta anónimo está construyendo la estructura del sentimiento de la desdicha a venir en términos siguientes:

Presentía alma mía

sin cesar inquieta en sus sueños-hedorras

aterrorizada.

Mosca azul presagiando la muerte,

un sinfín de desolación. ${ }^{5}$

Esta mención expressis verbis de la mosca azul proveniente del siglo XVII nos introduce al temario que queremos tratar en este trabajo. Es él de la mosca llamada en la lengua quechua chiririnka y el lugar extraordinario que ocupa en el folclore y en las creencias funerarias de los habitantes de los Andes. Ocupa la chiririnka un lugar sorprendentemente importante en las creencias andinas siendo un insecto que augura la muerte. Al jugar dicho papel, se hace notar de forma marcada su presencia en la cultura espiritual de los pueblos andinos que habitan las vastas zonas de la sierra yendo desde Ecuador, pasando

3 Arguedas 1981: 173-182 (capítulo: Mitos quechuas poshispánicos); SZEMIŃSKI, ZıóŁKowsKI 2014: 373-398 (capítulo: Inkaski mesjanizm); PosERn-ZIELIŃSKI 1974.

${ }^{4}$ SzEMIŃSKi 1992: 171-193.

5 Inkowie 2015: 72, (subr. por autores). 
por el Perú y llegando hasta Bolivia. ${ }^{6}$ Aparece desde hace siglos o quizás incluso desde hace milenios en el área de las creencias relacionadas con la muerte y en él de los ritos funerarios formalizados. Queda hasta hoy tema y objeto de referencias simbólicas en las canciones de luto muy antiguas que las mujeres cantan juntas mientras velan por el difunto. La melodía de esas canciones contiene rasgos onomatopéyicos imitando el zumbido de la chiririnka. ${ }^{7}$ Lo que atrae la atención es que la presencia de esta mosca va más allá del ámbito de la cultura relacionado directamente con la muerte. La encontramos igualmente en el folclore verbal en situaciones ajenas a las mortuorias sensu stricto - y, en particularidad, aparece en forma de muchos éxitos de la música popular peruana, las canciones llamadas huayno. Estas se cantan tanto en lengua quechua como en español, con frecuencia cobrando mucha popularidad y formando parte del repertorio de cantantes y grupos musicales conocidos y apreciados. ${ }^{8} \mathrm{El}$ sentimiento que transmiten es particular, expresivo, aunque no desprovisto de aspecto reflexivo, lejano a la sordidez de las canciones de luto europeas, constituyendo una imagen ilustrativa de las relaciones entre lo vital y la muerte tan diferentes en su percepción en ambas culturas.

Las investigaciones detalladas de fuentes etnográficas nos traen más sorpresas todavía, haciendo ampliar el ámbito de la presencia de la chiririnka en el marco de la cultura tradicional de los Andes. Es aquí pues donde aparecen numerosas indicaciones que prueban la existencia de otra "incorporación" muy aparente de este insecto más - a saber, aparece como una encarnación del alma humana. El papel animístico de la chiririnka a la par con su función profética de la anunciadora de la muerte va definiendo su figura como la de un insecto que tiene relaciones muy profundamente arraigadas y que vienen de muy antaño con la esfera de las creencias y las prácticas funerarias y, más ampliamente, con la de la escatología andina. Ambas "enarnaciones" suyas componen una cualidad complementaria que, en situaciones concretas, desvela su lado profético o animístico o bien, alternativamente, aparece jugando estos dos papeles al mismo tiempo.

${ }^{6}$ Este ámbito, dado en forma aproximada, abarca los terrenos de donde provienen los textos-fuente sobre la chiririnka conocidos a los autores del presente (teniendo en algunas zonas otros nombres locales). Parece probable, sin embargo, que el complejo de creencias similares relacionadas con esta mosca como augurio de la muerte aparezca al igual en otras zonas de la América del Sur.

${ }^{7}$ HuAmán 2004: 253.

${ }^{8}$ He aquí dos ejemplos populares y representativos de canciones peruanas contemporáneas sobre la chiririnka, provenientes de la región de Huancavelica: https://www.youtube.com/watch?v=5usZ-c2bd08 y otra de Ayacucho: https://www.youtube.com/watch?v=708UAZjkR34 (el 23 de septiembre de 2019). 
Da fe de forma significativa de este significado particular de la mosca el hecho de llamarla chiririnka Apu. ${ }^{9}$ El título Apu se atribuye a las encarnaciones masculinas de la fuerza y del poder - a los jefes de guerra, a los gobernantes y, también, a aquellas montañas que se consideraban como sagradas y a los dioses a quienes ellas representaban. Ahora, cuando este título se atribuye a la chiririnka, hace rotundamente resumir y explicar la naturaleza de este insecto poniendo en relieve su aspecto de una figura de gobierno y de poder emanante de sus conexiones entre lo animístico y lo escatológico lo que viene combinado con su papel como emisaria de la muerte. La chiririnka ha aparecido en la creación de José María Arguedas cuya obra, en la capa de la realidad que describe, la podemos tratar sin duda alguna como fuente etnográfica de pleno derecho. Este etnólogo eminente quien acumuló sus conocimientos en base a su propia vida (habiendo pasado su infancia y su tierna juventud entre los indígenas y los mestizos) a la de su educación universitaria y luego gracias a muchos años de su labor de investigación científica ha percibido, con la sensibilidad que le caracterizaba, la excepcionalidad y el papel particular de la chiririnka dentro de la cultura de los indígenas. Los contextos, las escenas y las situaciones en los que aparecía este insecto en sus libros hacen considerarlos como textos de índole científica regidos por las rigurosas reglas de la verdad y eso, aunque vengan expresados en el lenguaje literario.

Fig. 1. Mosca azul chiririnka - anunciadora andina de muerte y encarnación del alma humana.

Pasando a los detalles, cabe presentar con

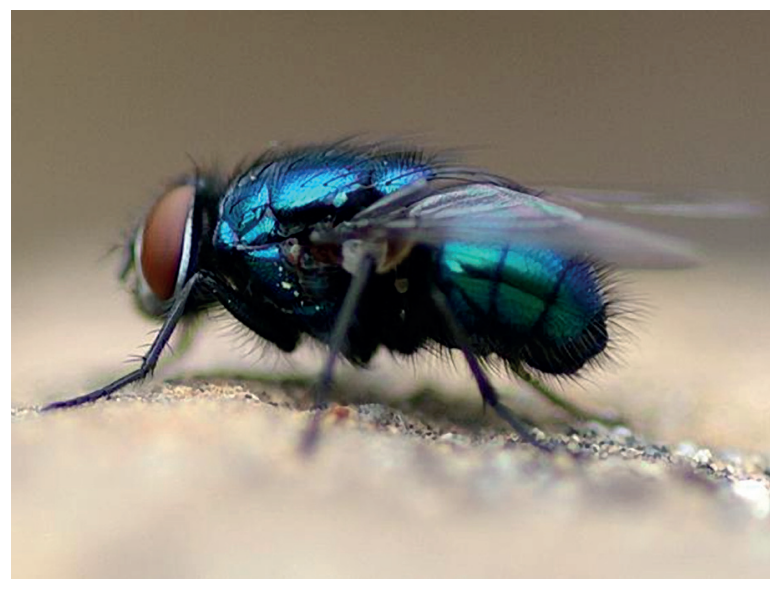

9 Por ejemplo, una de las obras de música y canto antes citadas en lengua quechua (nota de pie 8) lleva el título Apu Chiririnka, y en el texto de la canción vuelve a repetirse ese nombre en contextos diferentes. 
más detenimiento a la protagonista de nuestro relato [fig. 1]. La chiririnka es una mosca perteneciente a la familia califoridae cuyas muchas variedades viven en América del Sur. No vamos a detenernos para enumerar todos sus nombres latinos (siendo los más populares Calliphora vomitoria y Calliphora erythrocephala). Es más grande que la mosca doméstica común (presente también en los Andes) siendo su rasgo más característico su color metalizante y opalescente, lo más frecuentemente azul pero algunas veces teñido de verde o con colores cambiantes dentro de la gama verde-azul en función del ángulo bajo el cual la luz caiga sobre su cuerpo. Los mismos efectos de colores de arco iris pueden percibirse igualmente sobre sus alas. En algunas de sus subespecies atraen la atención sus ojos grandes de color rojo pero se dan igualmente otras en las que suelen ser negros como el resto de la cabeza de este insecto. En base a las descripciones etnográficas que han tomado en cuenta solo el color y el tamaño de la mosca podemos suponer que la chiririnka se da en forma de unas especies biológicas que guardan similitudes externas.

De la misma forma en la que su color azul constituye el rasgo visual esencial de la chiririnka, su rasgo más importante en cuanto a la percepción de su actividad que viene determinando su característica mítica es su reiterada aparición junto con el cuerpo de un hombre enfermo o herido o sea aquel que, de forma natural, se está aproximando a la muerte. Lo mismo corresponde a los ancianos cuyo potencial vital va apagándose por razones biológicas sin que esta situación tenga necesariamente su fuente en una enfermedad. En tales circunstancias la aparición de la chiririnka se trata como un augurio dada la convicción de que viene solo a aquellos que tienen prescrita e irrevocable la muerte. Despierta un temor particularmente profundo en los tiempos de epidemia. Su aparición en los sitios que hasta entonces no han sido tocados por la peste constituye un signo indudable de que la peste se los está acercando.

La chiririnka es un augurio de la muerte solo en caso del hombre. Vista junto a los animales no despierta temor ni se percibe como un augurio fatal alguno. Las fuentes etnográficas no han rescatado interpretación alguna que diga que su presencia junto a los animales domésticos presagiaría su moribundez. Despierta angustia solo cuando revolotea por encima del hombre de forma tenaz o bien si se posa sobre él - y ello en particularidad en cuanto éste se encuentra en un estado cercano al que peligre su vida o bien en uno que potencialmente le amenace.

Las convicciones acerca de la presencia de la chiririnka junto al hombre agonizante o que está en estado precedente a su agonía no pueden tratarse como producto de una fantasía ya que al igual de los miles de otros hechos reales éste también funciona en la consciencia colectiva de estos pueblos, fruto de la observación de la naturaleza circundante milenaria. Existen, sin duda alguna, 
razones racionales de este fenómeno, explicables por la ciencia. Las investigaciones que se han concentrado en los procesos químicos que acompañan la agonía del cuerpo humano, combinadas con las investigaciones sobre las "preferencias" de olor de estos insectos han llevado a formular unas hipótesis creíbles sobre este tema. Como se sabe, determinados estados de enfermedad dan como efecto la secreción por parte del cuerpo de sustancias olfativas de composición química muy determinada y que suelen ser indetectables por el hombre y, en cambio, lo son perfectamente por los animales. Varios experimentos diagnósticos llevados a cabo a este efecto han corroborado la capacidad empírica de ciertos animales a detectar enfermedades del hombre y, en particularidad, los cambios cancerosos. Se encuentran muy avanzadas las investigaciones sobre este tema y la literatura médica abunda en los tratados sobre el mismo. La eficiencia de la diagnóstica realizada con la participación de perros adiestrados para que sean capaces de detectar marcadores olfativos de las diferentes variedades del cáncer llega a situarse entre los 70 y los 90 por ciento. Vale la pena atraer la atención al hecho de que se refiere a estadios precoces de la enfermedad en cuestión o sea a periodos relativamente alejados del posible fallecimiento de la víctima. En esa etapa no se dan todavía manifestaciones visibles (o palpables) y el paciente aparece como si estuviese sano. Es difícil excluir la hipótesis de que la chiririnka tenga unas capacidades diagnósticas similares. Estamos ante un insecto con una sensibilidad olfativa excepcional. ${ }^{10}$ El fenómeno de concentrarse grupos de esta mosca alrededor de un hombre moribundo tiene seguramente una etiología científica, aunque esta última no se haya confirmado todavía. Eso podría explicar tanto los casos de su aparición posada o revoloteando sobre un hombre que evidencia estar cercano a la muerte, como, al igual, el hecho de que se posara sobre uno que no presenta todavía síntomas de entrar en el estado previo a la muerte. En el contexto andino tal circunstancia no corresponde a las enfermedades cancerosas ya que éstas casi no se dan en el mismo ${ }^{11}$ puede sin embargo, tener relación con la "percepción olfativa" de nuestra mosca de aquellos procesos químicos que se dan en las fases precoces de otras enfermedades típicas para esta parte del mundo o bien aquellos que acompañan la atrofia senil (atrophis senilis) en marcha.

Cabe señalar, sin embargo, que en el caso de que tal hipótesis se corroborara, solo traduciría cierta parte de los casos posibles de explicar siguiendo la orden dialéctica de las ciencias. De por su carácter, la misma iría sin embargo en contra del caudal autónomo de la lógica mítica que define de forma totalmente distinta las fuentes y la naturaleza de las enfermedades. El fenómeno de

${ }^{10}$ Connor 2008: 51-53.

11 RYN 2007: 129-130. 
la chiririnka sale pues mucho más allá del área de la medicina tal y como se entiende en Europa. Por ello el problema de la etiología científica de este fenómeno, fascinante sin duda alguna para un investigador de la medicina andina, parece ser de menor importancia en lo que va de la investigación etnológica. Los factores físicos y biológicos tienen que formar parte de la descripción sistemática de un fenómeno de carácter mítico, pero solo en la forma de interpretarlo tal y como le atribuye la cultura local.

La chiririnka es presente en un espacio de asociaciones mortuorias mucho más amplio que él que pudiese incluirse en una investigación científica. Es importante atraer la atención al hecho de que va presagiando cualquier muerte y no solo aquella que resultase de una enfermedad o del marasmo senil ( $\mathrm{ma}$ rasmus senilis). En el caso de una epidemia indica pues a las víctimas futuras, aunque las mismas todavía no han sido contagiadas. Presagia una muerte súbita, no precedida por síntoma alguno, apareciendo igualmente en sus variantes metafóricas y metonímicas (letargo, estado de tristeza o desesperación). El ámbito en el que aparece la chiririnka no cabe pues tan solo en la esfera de fenómenos puramente biológicos.

Vamos a servirnos de ejemplos provenientes de las fuentes, a comenzar por los más antiguos. Los encontramos en los artefactos arqueológicos de la cultura Moche de Trujillo de hoy. Probablemente fue la primera en notar la presencia de moscas en contextos mortales Anne Marie Hocquenghem, analizando la iconografía de Huaca del Luna y Huaca del Sol. ${ }^{12}$ Jean-Bernard Huchet también vuelve a este tema, ${ }^{13}$ discutiendo las imágenes de estos insectos que acompañan las representaciones de esqueletos humanos y las siluetas de prisioneros hechos en sacrificio [figs. 2, 3].

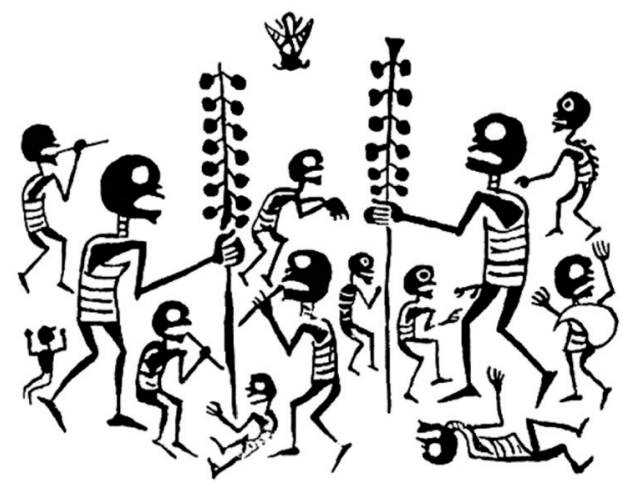

Fig. 2. Representación de una mosca volando sobre un grupo de esqueletos bailando y tocando música, Mochica III, Valle de Chicama, por: HuCHET 2017: fig. 9.

12 Hocquenghem 1981: 63-67, 69.

13 HuCHET 2017: 23-34. 


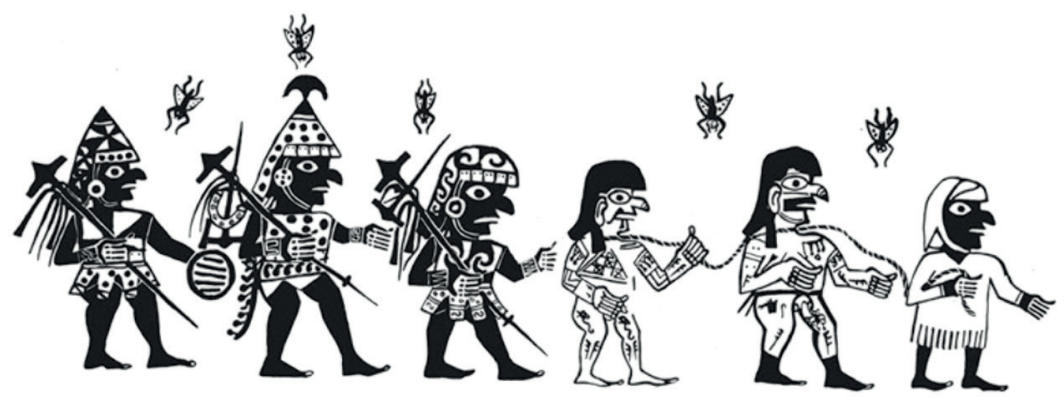

Fig. 3. Imágenes de moscas sobre prisioneros llevados a la muerte. Por: Huchet 2017: fig. 10.

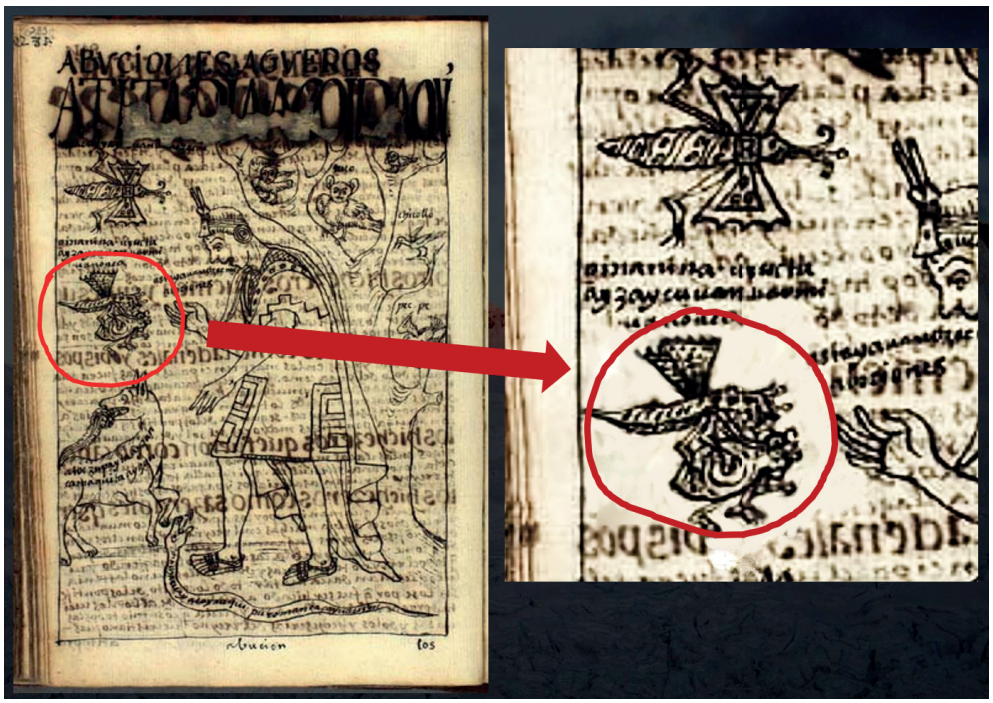

Fig. 4. Supuesta mosca chiririnka en el dibujo de la Crónica de F. Guamán Poma de Ayala,1615 (Biblioteca Real de Copenhague).

Se puede suponer que la "mosca de la muerte" también aparece en las primeras fuentes escritas. Los conocedores de la historiografía andina dicen, medio bromeando, que en los 397 dibujos que contiene la famosa Crónica de Felipe Guamana Poma de Ayala (1615) puede encontrarse material iconográfico para desarrollar cualquier tema relacionado con la historia y la cultura de los Incas. Hemos estudiado esta obra esperando encontrar allí huellas de la chiririnka. El resultado aparece dudoso y no conclusivo, no obstante, digno de ser 
mencionado. En uno de los dibujos ${ }^{14}$ [fig. 4] divisamos a un indígena rodeado por animales que se perciben como hostiles u ominosos. Entre ellos encontramos dos insectos: una mariposa negra la que los indígenas andinos igualmente percibían como presagio de la muerte ${ }^{15}$ y uno otro, cuya forma resulta difícil de identificar de manera concluyente que viene firmado en quechua: "Nina nina curucta ayzaycuuan, uarmi uanonca", lo que el traductor tradujo como: "Una nina nina (una especie de avispa) ha arrastrado un gusano, mi mujer va a morir". Tanto la firma como su traducción no acaban de ser totalmente claros. Nina nina no tiene que ser necesariamente "una especie de avispa" ya que en la lengua quechua puede significar igualmente "un insecto opalescente" especie de libélula. ${ }^{17}$ La pregunta que uno puede plantearse es: ¿puede esconderse igualmente bajo este nombre una mosca? La forma de su abdomen y la de sus alas se asemejan más a una libélula y no a una mosca o una avispa. El nombre nina nina no sugiere una chiririnka dado que ninguno de sus significados que aparecen en los diccionarios del quechua no corresponde a una mosca. En dicho dibujo el insecto lleva atrapado en sus patas a otro insecto (¿será una araña?) lo que seguramente viene asociado a un tramo perteneciente a la esfera de las creencias o bien viene de la observación de la naturaleza. ${ }^{18}$ También despierta dudas la identificación de aquel insecto volante como avispa ya que, aparte de que su forma no sea parecida a este otro insecto, al mismo tiempo tampoco despierta en los indígenas asociaciones negativas algunas ni augurio la muerte humana de forma que su colocación en el ámbito del bestiario del mal no encuentra fundamento suficiente. Tanto más es así que en la parte final de dicha firma leemos estas palabras tan intrigantes: "mi mujer va a morir" lo que tiene que interpretarse unívocamente como un augurio de la muerte a venir. Las fuentes que hemos consultado indican que en los Andes solo la chririnka y la mariposa negra se perciben como augurios que presagian la muerte de una persona ${ }^{19}$ de manera que el texto de esta firma indicaría que se tratase más bien de nuestra mosca antes de cualquier otro insecto. Lo que despierta más dudas es el

14 Guamán Poma de Ayala 1615: fot. 281 [283].

15 Carranza Romero 2005: 16; Arguedas 2011: 143-144.

16 En el diccionario: Carranza Romero 2003: 40, no aparece la traducción de nina nina como "avispa". En cambio en el diccionario: Diccionario quechua-español Runasimi en línea en Aulex, comp. por P. Jacobs. 2001 (http://runasimi.de) la "avispa" aparece como una de las traducciones posibles de la expresión nina nina.

${ }^{17}$ En base a la información obtenida por correspondencia de parte de profesor Jan Szemiński.

${ }_{18}$ Nuestra intuición nos sugiere que el dibujo del insecto que lleva volando a otro insecto no es una fantasía volátil del dibujante. Tendría que buscarse la solución de este enigma en las capas de la tradición rica de los mitos y las creencias andinas y, también, en la observación del universo animal andino.

19 Carranza Romero 2005: 12-18. 
dibujo mismo ya que este insecto, aun si tomamos en cuenta una supuesta falta de destreza de su autor, no se parece a una mosca. Resulta pues dificil la interpretación de este dibujo sin aportar informaciones de fuentes adicionales para formar una respuesta concluyente. Nos consta que a caballo de los siglos XVI y XVII la chiririnka ya estaba presente en las creencias de los indígenas pudiendo pues perfectamente hacer su aparición en la Crónica de Guanama Poma de Ayala. Queda un misterio sin resolver la duda sobre si este dibujo que acabamos de describir puede ser el primer retrato de nuestra mosca o no.

Quedando en el ámbito de las fuentes más antiguas aparece la pregunta sobre las posibles influencias de las creencias y del folclore ibérico (o más ampliamente: europeo) sobre la formación de la figura de la chiririnka en el ámbito de la cultura andina. No vamos, sin embargo, a desarrollar este tema ya que exigiría realizar un análisis detallado de un amplio material etnográfico proveniente de Europa lo que saldría del marco de este trabajo. ${ }^{20}$ Nos permitimos señalar tan solo el hecho de que en las culturas populares europeas del medioevo (y no raras veces subsistente hasta hoy en día) la mosca despertaba asociaciones negativas, aunque pocas veces aparecía como un augurio de la muerte. En diferentes partes del continente europeo, incluyendo la Galicia española, la mosca es una de las encarnaciones de la bruja o del diablo. ${ }^{21}$

La asociación que sí encontramos, aunque esporádicamente, entre otras en los terrenos donde habitan los Eslavos, ${ }^{22}$ es la asociación de la mosca con el alma humana. "Tardará aún la chiririnka que viene un poco antes de la muerte"23 - dice en su cuento Arguedas, el autor de La agonía de Rasu-Niti - es una descripción incomparable de la famosa "Danza de las Tijeras" peruana, la muerte de un danzante anciano y el nacimiento simbólico de su sucesor. Esta obra $^{24}$ extraordinaria y tratada en numerosos trabajos es una obra maestra literaria pero, al mismo tiempo, un análisis etnológico multicapa del mito del retorno eterno - de la muerte que da lugar a un nacimiento y su crecer hacia la muerte cuyo ritmo es dado por tambor andino que "mueve el mundo entero". ${ }^{25} \mathrm{La}$ espera de la llegada de la chiririnka constituye la última etapa de la entrada en la muerte la que, sin embargo, aniquila tan solo el cuerpo del danzante. La danza sigue retomada y continuada por un danzante-sucesor joven en el que penetra el

${ }^{20}$ Este temario ha sido abundantemente tratado en el trabajo citado del CoNNOR 2006, (véase la nota de pie 10).

${ }^{21}$ Merino 2000: 208-209.

22 MosZYŃSKi 1967: 539, 540, 550, 553.

23 ARguedas 1977: 171.

${ }^{24}$ HuAMÁN 2004: 252; GONDOR-WierCiOCH 2009: 218-219.

${ }^{25}$ Esta designación aparece en la colección de mitos andinos más antigua - los mitos de Huarochiri (escritos en quechua a caballo de los siglos XVI y XVII). Es esencial para entender y sentir la música y la danza en la cultura de la zona andina. Véase: Dioses 2012 [1966]: 41. 
alma del maestro anciano. Arguedas alude aquí claramente al concepto andino del alma humana que, abandonando el cuerpo de la persona que muere, puede encontrarse un lugar en otro hombre. La presencia de la chiririnka en este rite de passage transcendental es una alusión a la dualidad de su naturaleza: como la que augura la muerte y, al mismo tiempo, la que encarna al alma del muerto.

La obra de José María Arguedas contiene material etnográfico precioso. Tiene un valor de fuente pudiendo tratarse como una síntesis de muchas tradiciones transmitidas por separado, dado que aquellas no conllevan licencia poética. Son, en cambio, documentos etnográficos rigurosos expresados en una forma literaria incomparable. Su sensualismo y su sensualidad emocional, ajenos a la narración de textos científicos típicos, se vuelven aquí un elemento de la descripción de la realidad indispensable y enriquecedor. En Los ríos profundos, un libro en gran medida autobiográfico encontramos unos recuerdos del autor excepcionalmente sugestivos de lo que había sido la epidemia del tifus que infestó a la ciudad andina de Abancay y a las aldeas de su vecindad. Arguedas vivía allí en ese entonces (los años 20 del siglo XX) en un internado estudiando en una pequeña escuela dirigida por sacerdotes. La atmósfera del temor creciente ante la peste que iba eliminando a un número de habitantes cada vez mayor fue sensibilizando particularmente a la gente que empezó a divisar cada vez mejor aquellos signos que interpretaban como augurios de la muerte por venir.

En aquellos días sentía terror cuando alguna mosca caminaba sobre mi cuerpo, o cuando caían, colgándose de los techos o de los arbustos, las arañas. (...) Creían en el pueblo que eran la muerte. A las gallinas que cacareaban en el patio o en el corral, las perseguían, lanzándoles trozos de leña, o de pedradas. Las mataban. (...) La voz de las gallinas, imprecisa, ronca, estallaba en el silencio que en todas las casas cuidaban. El viento no debía llegar con violencia, porque en el polvo sabían que venía la muerte. No ponían al sol los carneros degollados, porque en la carne anidaba el chiririnka, una mosca azul oscura que zumba aun en la oscuridad, y que anuncia la muerte; siente, al que ha de ser cadáver, horas antes, $\mathbf{y}$ ronda cerca. ${ }^{26}$

Puede considerarse como complemento de esta descripción la tradición según la cual los indígenas trataban muchas veces de matar las chiririnkas para prevenir así la muerte que presagiaban. ${ }^{27}$ En otro lugar el autor vuelve a evocar el recuerdo sobre la anunciadora de la muerte:

26 Arguedas 2001: 184 (subr. autores).

27 HuAMÁN 2004: 252. 
Una chiririnka empezó a zumbar sobre mi cabeza. No me alarmé. Sienten a los cadáveres a grandes distancias y van a rondarles con su tétrica musiquita. ${ }^{28}$

Encontramos la mosca que aparecía junto con la muerte en algunas de las obras de Arguedas. Su texto no siempre la llama directamente la chiririnka, pero su contexto no deja lugar a dudas. En su emocionante novela El zorro de arriba y el zorro de abajo, por ejemplo, las moscas vienen a acompañar la muerte de los indígenas quienes, habiendo trabajado en las minas, aparecen mortalmente enfermos de neumoconiosis: "Moscas comían su negro carbón que de su nariz salía". ${ }^{29}$ El motivo de moscas aparece en algunas obras de Arguedas más, entre otras en Todas las sangres donde el asesinato del hacendado don Lucas odiado que tanto oprimía a los indígenas viene anunciado por una bandada de chiririnkas que revoloteaba sobre su cabeza. ${ }^{30}$ De este mismo libro vale la pena citar un párrafo de la canción velatoria llena de sufrimiento cantada por la mendiga Gertrudis cuyos ojos lloran dejando caer gotas de sangre. Contiene dos augurios de la muerte populares en las culturas andinas: la figura de la mosca chiririnka y un aullido ominoso de perros:

\section{La mosca que anuncia la muerte}

aletea en la puerta del templo;

torrentes de lodo amenazan;

los perros están aullando todos

en la plaza. ${ }^{31}$

El motivo de la chiririnka aparece también en uno de los poemas mesiánicos presagiantes el retorno del Inca que Arguedas tradujo del quechua:

Lago frío durmiendo, roca negra,

mosca, anunciando la muerte,

corazones humanas bondadosas

en el mundo entero.... . $^{32}$

Las obras aquí citadas a la par del texto del siglo XVII que hemos citado en la introducción del presente trabajo amplían de manera sutil, pero inevitablemente el área de actuar de la "anunciadora de la muerte" abarcando estados de muerte metafóricos o metonímicos. Un dolor y una desesperación que no tienen límites le hacen a uno caer en una suerte de letargo ("sueño-pesadilla")

\footnotetext{
${ }^{28}$ Arguedas 2001: 187 (subr. autores).

29 Arguedas 2011: 140.

30 Huamán 2004: 254.

31 Arguedas 1964: 423 (subr. autores).

${ }^{32}$ Inkowie 2015: 87 (subr. autores).
} 
- un estado de suspensión entre la vida y la muerte en el que se acerca volando la mensajera volante del "más allá".

Otro ejemplo hace aparecer la chiririnka en un círculo metonímico de la muerte al que pertenece igualmente el sueño normal y corriente. En una de las fábulas andinas arraigada en los mitos arcáicos aparece un pastor joven y guapo llamado Inti (en quechua su nombre hace referencia directa y ostensible al Sol), su madre, el pájaro rojo Pisacca y un par de zorras. ${ }^{33}$ Vamos a prescindir de una narración más detallada de este texto para concentrarnos en su final en el que Inti recurre a una trampa para recuperar la flauta que tenían en su dominio las zorras. Siguendo un consejo de la mosca chiririnka se tumba para hacerse pasar por muerto y ella revolotea sobre él emitiendo un zumbido intenso. Por la presencia de la "mosca de la muerte" las zorras concluyen que Inti está muerto. Se le acercan y en ese mismo momento Inti se levanta bruscamente y logra recuperar su propiedad. No es una coincidencia que el motivo de pretender el sueño - metonimía de la muerte - aparezca en esta fábula siendo significativo el que sea un invento de la misma chiririnka "que muchas veces observa la lucha entre la vida y la muerte". ${ }^{44}$ Simular el sueño es sinónimo de simular la muerte. Sin lugar a dudas obtenemos así la información que la presencia de la chiririnka que zumbe revoloteando por encima del hombre define a este último como muerto. La convicción de las zorras refleja pues la convicción idéntica de los hombres quienes ven una relación muy estrecha entre la mosca y la muerte. La chiririnka corrobora de forma evidente el fallecimiento del hombre que ya se hizo efectivo o lo anticipa volviendo muerto de facto al quien sigue vivo todavía, pero vive marcado por la sentencia de muerte irrevocable. Otro valor más de esta fábula es su arcaismo indudable cuyo origen remonta a los tiempos precolombinos lo que confirma nuestra hipótesis de que el tema de la chiririnka tiene un origen local y muy antiguo.

Los ejemplos que se acaban de citar, seleccionados por entre muchos otros que guardan similitud a ellos prueban que la función de la mosca chiririnka en las culturas populares andinas no se limita exclusivamente a la situación de la muerte sensu stricto. La figura de esta mosca puede jugar el papel de una figura retórica, por ejemplo, en una lamentación o una canción, fortaleciendo los medios de expresión de los sentimientos trágicos que oscilan en torno a la muerte. Ello da fé de la fuerza e intensidad de esta creencia y su arraigo en el sistema más amplio de la visión del mundo mítica. Vienen complementando esta tesis los ejemplos de la asociación que tiene la chiririnka a elementos de la realidad concretos. Carlos Huamán, al analizar áreas semánticas del significado de diversos elementos y alusiones escondidas en la obra de Arguedas, habla de las

33 Ramirez Chacaltana 2014.

34 Ramirez Chacaltana 2014. 
"chiririnkas - militares y policías" ya que los indígenas percibían a estos últimos como traedores de la muerte. ${ }^{35}$ En el siglo XIX esta asociación se vio reforzada por el color azul de los uniformes de las fuerzas armadas de Chile cuyos soldados se volvieron famosos por su extraordinaria crueldad hacia los peruanos y los bolivianos durante la famosa "Guerra del Pacífico", llamada también "Guerra del Salitre" (1879-1884). Los soldados chilenos azules se volvieron para los habitantes de esta parte de los Andes sinónimo o encarnación del diablo y como tales empezaron a funcionar en el habla popular [fig. 5] "Cuando bebía le entraban diablos azules, se hacía propenso a querellas y peleas" 36 - contaba en los años '70 del siglo XX una mujer indígena de Cuzco, con toda probabilidad inconsciente de la génesis del término "diablos azules". Otro ejemplo de esta ampliación de la esfera de asociaciones a la chiririnka es el nombre universalmente usado "flor de la muerte" para designar una planta de la especie tagetes con pétalos amarillos o amarillos y naranja sobre los cuales a esta mosca le gusta a posarse [fig. 6]. Esta flor emite el olor de carne podrida lo que fortalece aún más esta asociación. Otro género de flor de forma de un zapatito que frecuenta con gusto la chiririnka se suele llamar "zapatito de los muertos" (en la lengua quechua ayak'zapatilla). Sus ramos se suelen llevar a las tumbas y con frecuencia crecen sobre las tumbas y en lugares húmedos, escondidos en la sombra. El motivo del "zapatito de los muertos" aparece también en la obra de Arguedas:

Pensé en ese lobulillo afelpado - ayak'zapatilla le llaman en quechua (zapatilla de cadáver). (...) El ayak'zapatilla florece alegremente, con gran profusión, en las paredes húmedas. Que sostienen a los andenes sembrados, en los muros que orillon los caminos; tiembla con el aire; y los wayronk'os, los grandes moscardones negros, lo buscan. ${ }^{37}$

Una investigación más profunda abarcando el área de las diferentes variantes de la lengua quechua y sus dialectos locales que incluyese el folclore andino no escrito (canciones, recitaciones, proverbios y dichos, adivinanzas, etc.) demostraría seguramente muchas asociaciones y relaciones de diferentes objetos y fenómenos con la chiririnka más. Nosotros no disponemos de materiales tan amplios apoyando nuestra convicción en nuestras propias experiencias que hemos tenido a la hora de investigar otros animales presentes en las culturas populares de los pueblos andinos (y, sobre todo, en el caso del zorro).$^{38}$ Como

35 HuAMán 2004: 254.

${ }^{36}$ Inkowie 2015: 266.

37 Arguedas 2001: 114-115; Huamán 2004: 260-261, en donde el autor describe ampliamente el significado del "zapatito de los muertos" en relación con las creencias y prácticas funerarias y el motivo de esta flor en la obra de Arguedas.

38 JoDŁOWSKA, MĄKa 2015: 189-229. 


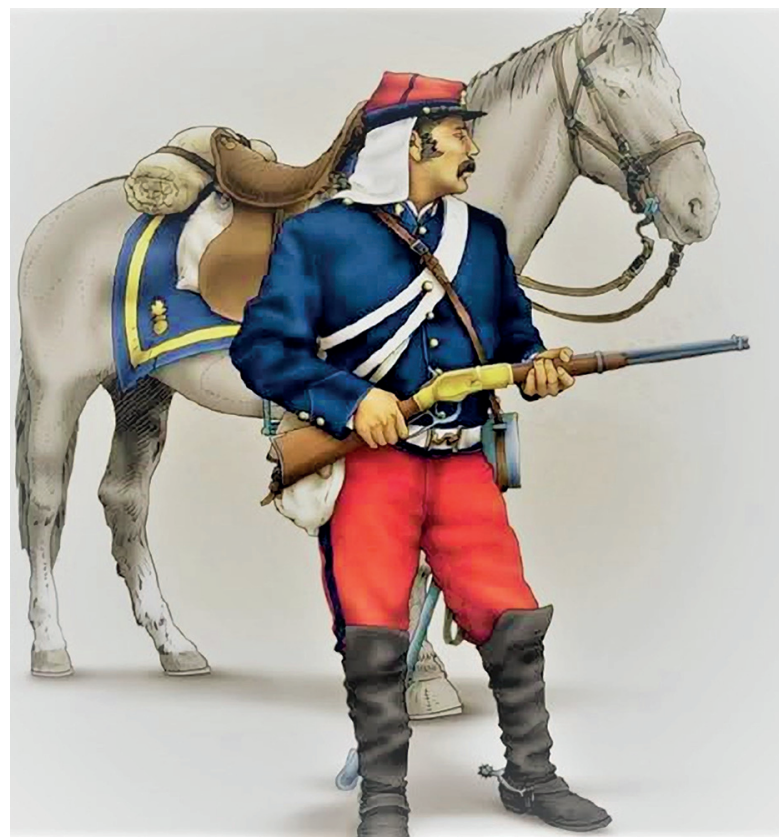

Fig. 5. El soldado-chiririnka del período de la "Guerra del Pacífico” (1879-1884).

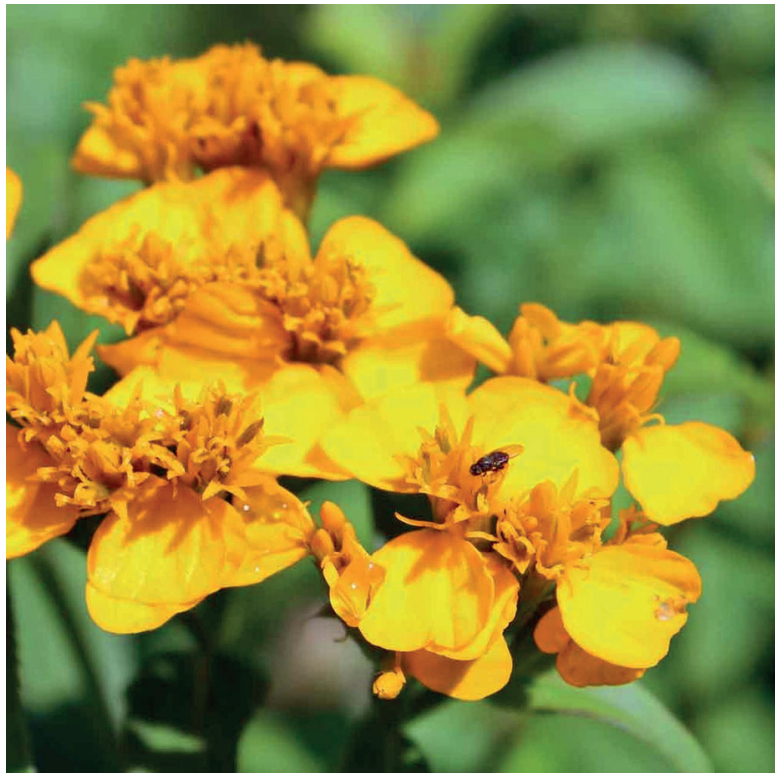

Fig. 6. Chiririnka en una de las variedades de caléndulas (Tagetes lucida) - una flor dedicada a los muertos. 
efecto de estas investigaciones hemos logrado comprobar lo sorprendentemente amplio que es el área de asociaciones a este animal en concreto y el polisemantismo de su mismo nombre, presente en muchas esferas en el entorno humano y con frecuencia en unas que no aparentan tener nada que ver con él. La lógica que rige tales asociaciones parece corroborada por la posición de la posición de Lévi-Strauss que ha constatado: "el lenguaje figurado fue el primero en nacer y lo último que se encontró fue el sentido propio", y que la metáfora era "una forma primera del pensamiento discursivo". 39

La tesis que hemos formulado sobre el arraigo profundo de la "mosca de la muerte" en la tradición andina y sobre sus numerosas asociaciones sistémicas a las diferentes esferas de la cultura se ejemplifica particularmente en aquellas variantes de esta creencia que ven en la chiririnka una encarnación del alma humana. Encontramos este motivo ya en el conjunto de los mitos andinos más antiguo al que Arguedas llamó poéticamente poniéndole el título Dioses y hombres de Huarochiri:

Y así, dicen que a la salida del sol, en Yarutini, el muerto aparecía, llegaba. En los tiempos antiguos, afirman, que dos o tres moscas muy grandes se posaban sobre la ropa nueva que llevaba la mujer. A estas moscas las llamaban "llasca anapilla". 40

Tal y como ya hemos mencionado, puede encontrarse la alusión a la dualidad de la naturaleza de esta mosca como anunciadora de la muerte y como encarnación del alma humana ya en el famoso cuento de Arguedas La agonía de Rasu-Niti. Este mismo motivo va apareciendo tanto en materiales etnográficos que han registrado las elocuciones de los indígenas quienes, expressis verbis, hablaron del alma que sale volando del hombre en forma de la chiririnka azul ${ }^{41}$ como en los textos folclóricos. El profesor Jan Szemiński lo ha expresado, sin dejar lugar a dudas, en estos términos: "Las moscas azules se consideran hasta hoy en día las almas de los muertos".$^{42}$ En el Perú central y meridional y también en Bolivia se han registrado diversas variantes del mismo cuento una versión andina del mito órfico llena de poesía. ${ }^{43}$ Una de ellas proviene de la zona de la ciudad de Arequipa estando relacionada con la montaña Coropuna (6425 m.s.n.m) ubicada al noroeste a unos 150 kilómetros de la misma en línea recta. Es un macizo volcánico cubierto con la capa de nieve y glaciar que desde hace miles de años es considerada una de las montañas más sagradas - Apu

39 LÉVI-STRAuSS 1965: 148.

40 Dioses 2012 [1966]: 157.

${ }^{41}$ Gose 2004: 156.

42 Inkowie 2015: 72 (subr. autores).

43 Cipolleti 1984: 421-432. La autora cita, entre otros, un cuento incluido en el trabajo de J.M. Arguedas: Puquio. Una cultura en proceso de cambio. La religión local (1956). 
- en Perú [fig. 7]. La rodea un amplio complejo de mitos indígenas y una herencia cultural extremadamente rica relacionada con la historia de las zonas aldeañas. Ocupa esta montaña un lugar muy importante en las creencias escatológicas de los indígenas quienes creen que en sus entrañas permanecen las almas de los muertos. Numerosos cuentos que incluyen su tema van reflejando unos conceptos del más allá complicados dentro de la cosmovisión andina los que, dada la extrema amplitud de este tema, no vamos a presentar aquí. ${ }^{44}$

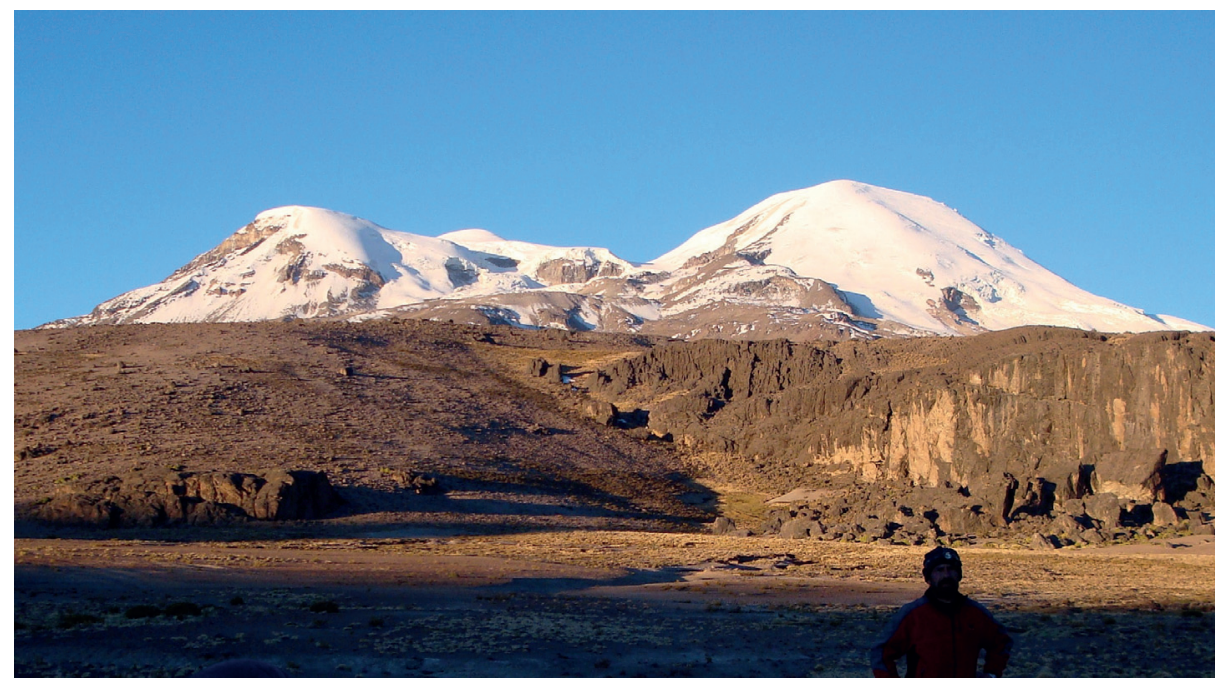

Fig. 7. Nevado Coropuna Apu (6425 m.s.n.m.) - una montaña sagrada de los indios. Lugar mítico de los muertos

Uno de los mitos órficos con origen en estas tierras cuenta la historia de un indígena que, no pudiendo conciliarse con el hecho de que su mujer había muerto, salió de su aldea rumbo a Coropuna para encontrar el alma de su esposa en el país de los muertos. A sus puertas encontró a un guardia en forma de San Francisco. La persona del santo cristiano, aparentemente tan sorprendente en este sitio, es uno de los ejemplos del sincretismo andino cuyas manifestaciones resultan a veces en unos conjuntos imprevisibles o una reinterpretación de motivos de las dos religiones - la cristiana y la indígena. El santo no le dejó entrar al interior de la montaña pero, conmovido por la rogación del indígena entristecido, le trajo un pedazo de caña diciendo que ella contiene en su interior el alma de su mujer. Le encomendó al mismo tiempo que lo guardase encerrado entre las palmas de sus manos hasta que no llegue a su

${ }^{44}$ En cuanto al tema de la Coropuna véase, entre otras: Gose 2004: 154-166; VALDERRAMA FERnÁNDEZ, EsCALANTE GUTIÉRREZ 2012: 233-264. 
casa. Este, sin embargo, no pudo contener su curiosidad, abrió las manos antes y vió la caña sobre la cual estaba posada el alma de su mujer en forma de la mosca azul - la chiririnka. Por desgracia, no logró a tiempo volver a encerrarla entre las palmas de sus manos - la mosca, una vez liberada, se fue volando de vuelta hacia la Coropuna.

La convicción de que la chiririnka presagia la llegada de la muerte y que puede ser encarnación del alma humana constituyen dos corrientes muy próximos uno al otro de esta creencia que hace destacar de forma espectacular a la mosca dentro del universo de la naturaleza tan rico, atribuyéndole unos rasgos únicos y haciéndole relacionarse con la esfera de la cultura. En función del contexto concreto prevalece una $\mathrm{u}$ otra de estas corrientes. Hemos atraído ya la atención al ámbito tan imponente en el que aparece la chiririnka en áreas de referencia de ambas corrientes, tanto reales como metafóricas y metonímicas, reflejándose en una presencia espectacular de la mosca en el folclore andino en lamentaciones, cantos y, en particularidad, en cuentos populares que, desde el punto de vista formal, oscilan entre fábula y mito. Para terminar, vamos a complementar el recuento de las formas de la presencia cultural de la chiririnka presentando un ejemplo significante e importante que prueba que su figura ha penetrado también a la esfera de la magia y la del rito. Las fuentes etnográficas $^{45}$ han registrado pues una costumbre peculiar que se practica el día de Todos los Santos en las aldeas del Perú central y meridional. Los indígenas creen que en ese momento particular las almas de los muertos se vuelven chiririnkas y vuelven a sus casas para saciar su hambre. Por ello la noche anterior se les prepara una olla rellena de grasa de llama y una mecha alrededor de la cual se acomodan asientos para las moscas en forma de unos ladrillos adobe cubiertos, para mayor comodidad, con pedazos de piel. El olor de la grasa quemada es la comida para las almas-chiririnkas quienes vienen durante la noche. Dicha costumbre ostenta rasgos de prácticas de ofrenda universales durante las cuales el componente más importante era la grasa - quemada y transmitida a la deidad en forma del humo que se exhalaba. Incluso en los casos de ofrendas consistentes en la quema de animales enteros, de las llamas, por ejemplo, la grasa era la parte que le correspondía solo y exclusivamente al destinatario divino de la ofrenda comiendo la carne los demás participantes de la ceremonia. ${ }^{46}$ En las culturas andinas la grasa gozaba de un rango particular constituyendo la sustancia más importante del cuerpo humano y animal que contiene el potencial de

45 Valderrama FernándeZ, EsCalante GutiérRez 2012: 264.

46 Se han descrito y documentado ejemplos de ceremonias de los incas practicadas de esta forma en base a extractos de fuentes de los siglos XVI-XVIII en: SzEMIŃSKI; ZıóŁKOwSKi 2014: 220, 221 y otros. Véase también: ConNOR 2006: 52-53. 
la vida y de la fertilidad. ${ }^{47}$ En este caso la ofrenda se ha reducido a lo esencial o sea a la grasa pura manteniéndose los vivos alejados sin participar en el banquete de las chiririnkas. Esta costumbre reviste una forma perfectamente regional, andina, reuniendo en un proceso sincrético un motivo muy antiguo proveniente de las creencias locales y los rituales cristianos celebrando los muertos practicados el día de Todos los Santos. Vale la pena, sin embargo, atraer especial atención del lector a un detalle: la importancia que tiene el hecho de que las almas-chiririnkas vengan con visita por la noche. Es, pues, la única mosca "que zumba aun en la oscuridad y que anuncia la muerte". ${ }^{48}$ Las moscas no son, sin embargo, animales nocturnos siendo la chiririnka la única excepción a esta regla pareciendo como si se rigiera por otras leyes distintas a las demás de su especie. Este rasgo extraordinario se percibió e interpretó situándola en su orden mítica particular.

Un análisis sistémico de las creencias relacionadas con la chiririnka pone al descubierto su complejidad que es mayor de lo que podría resultar de tradiciones particulares transmitidas cada una por separado. El esbozo que acabamos de presentar pone de relieve lo múltiple de sus motivos, aunque dentro del marco este trabajo no hayamos llegado a analizar este tema exháustivamente - y lejos de ello. Intuimos que si se profundizara tan solo la investigación del motivo de la encarnación del alma humana en la chiririnka se descubrirían relaciones mayores y más profundas de la mosca con los contenidos de la mitología andina. Cualquier investigación de las relaciones que tiene la chiririnka con alma humana exigirían conocer la estructura compleja de las creencias animísticas y, en particularidad, el concepto de la existencia en cada hombre de tres almas $^{49}$ siendo perfectamente determinado el papel y la función de cada una de ellas. De hecho, cada una de las mismas tiene otra relación con el cuerpo, implicando, por ende, tanto las formas de prácticas funerarias ritualizadas adecuadas, como los tratamientos terapéuticos aplicados por curanderos, chamanes y brujos andinos. ${ }^{50}$ Considerado en relación con las creencias sobre la chiririnka este concepto sube el grado de complicación del tema. Si analizamos, en cambio, la lógica de los símbolos en la tradicón andina, se va ampliando el área de referencias hacia y abarcando, entre otras, la esfera de percepción y valoración de las sensaciones sensoriales: sonidos, olores y colores.

47 "En quechua wira, «la grasa», es símbolo de vida y de vitalidad" - Inkowie 2015: 152 (comentario de Jan Szemiński sobre unos fragmentos de la relación de Cristóbal de Molina del s. XVI).

48 ARguedas 2001: 184 (subr. autores).

49 Tratan los detalles de las creencias relacionadas con el concepto de tres almas, entre otros.: Gose 2004: 156; VALDERRAMA FernÁNDEZ; EsCALANTE GutiérReZ 2012: 154-166. El motivo de "algunas almas" aparece también en la prosa de Arguedas.

${ }^{50}$ RYN 2007: 198-237. 
En el caso de la chiririnka, la esfera de estímulos auditivos tiene una importancia particular. En la literatura se suele subrayar que su nombre es una onomatopeya imitando el sonido de zumbido característico que emite que emite esta mosca particular, y distinto de y distinto de los sonidos emitidos por otros insectos. ${ }^{51}$ Hemos dicho ya que este sonido, aparte de ser reflejado en el nombre de la mosca, se ha visto traducido en la melodía de algunas de las canciones de luto que las mujeres cantan al velar al muerto. No cabe duda de que el tono del zumbido de este insecto, inducido por la frecuencia del batido de sus alas, influencia determinadamente las sensaciones síquicas que resiente el hombre. No es de excluir que la chiririnka emite impulsos fónicos de carácter de infrasonidos que despiertan sentimientos de inquietud o incluso temor subconscientes. ${ }^{52}$ Este efecto constituye un factor sicológico y, sin embargo, el mismo sonido que lo origina se ha incluido como parte del complejo de creencias sobre la mosca y se ha vuelto un estímulo separado del universo de los sonidos de la naturaleza atribuyéndole rasgos de contenidos culturales bien definidos. Su percepción no queda desprovista de reflexión; lejos de ello, viene activando un contexto de asociaciones a la muerte bien visible y fuertemente emocional.

A la par de ello, no queda sin importancia la valoración de las sensaciones olfáticas que, como las gustativas, se originan en un grado elevado en la misma cultura de los pueblos andinos y no en la biología. Los sitios en los que aparece la chiririnka se asocian al hedor de la pudrición y de la descomposición. Estas moscas se nutren devorando la carne muerte de animales posándose igualmente sobre los cuerpos de hombres muertos o en estado de agonía. Ponen huevos de los que nacen larvas en medio de la materia muerta podrido. Se reúnen en sitios en donde reina la suciedad y donde va muriendo el tejido orgánico de sus huéspedes. En la prosa de Arguedas y, en particularidad, en su libro El zorro de arriba y el zorro de abajo, van apareciendo de forma recurrente en las descripciones de tales sitios (p.ej. la bahía de Chimbote) y, también, en imágenes mostrando suciedad y descomposición. ${ }^{53}$ El hedor que se siente en aquellos sitios despierta asociaciones a la muerte inequívocas y, más ampliamente, a rasgos y características que se perciben como profundamente peyorativos.

Investigando el tema con respecto al simbolismo de la chiririnka resultaría imposible pasar por encima del estímulo visual de primera importancia que constituye su color azul marino. Mercedes López Baralt, al analizar la metafórica de Arguedas que aparece tanto en su prosa como en sus traducciones de

51 HuAMán 2004: 252.

52 Sobre el tema de infrasonidos emitidos por la Naturaleza y por objetos (p.ej. por algunos de los instrumentos de música) y su influencia a las emociones que experimenta el hombre véase: Michta 2013: 73-92.

53 HuAMÁN 2004: 253-255. 
obras escritas en quechua que contienen el motivo de la chiririnka, se refiere al color azul marino como una alusión a lo infinito que representan el cielo y el $\operatorname{mar}^{54}$. El azul marino incide en el sistema parasimpático del hombre dando impresión de frío, de alejarse (los elementos del paisaje lejanos se vuelven azules) y, también de nostalgia y de anhelo. En algunas de las partes de Mesoamérica, es el caso de los aztecas, por ejemplo, el azul marino se asociaba con el más alla al que pasaban los esclavos sacrificados apareciendo este color de forma reiterada en diferentes ritos de sacrificio ${ }^{55}$. Los analistas de la simbología de colores atraen la atención hacia el azul marino como un color de luto en varias áreas del mundo. "Las manchas azules que aparecen tras la muerte no han pasado inapercibidas por los hombres por lo cual podría incluirse el color azul - aunque sea de forma limitada - en la gama de colores propios de los muertos. (...) «La proximidad síquica» del azul marino y del color negro puede notarse en varios idiomas y varias zonas geográficas". ${ }^{56}$ Las moscas azules como mensajeras del mal que amenazan la salud y la vida de los hombres aparecen, entre otras, en las creencias escandinavas ${ }^{57}$. En las tumbas de la antigüedad egipcia se han descubierto esculturas de moscas azules de tamaño natural aunque su propósito queda poco claro ${ }^{58}$ Para demostrar relaciones sistemáticas del color azul de la chiririnka con los demás elementos simbólicos que compone su figura tendría que procederse a una investigación profunda sobre las fuentes disponibles y a un análisis del papel del color azul marino en las culturas andinas dado que incluso los mejores estudios sobre los colores y su papel en la cultura ${ }^{59}$ no contienen datos suficientes procedentes de esta parte del mundo.

El ejemplo de la chiririnka que hemos descrito en el presente trabajo a modo de esbozo nos ha dado como resultado la imagen de una riqueza de su contenido que viene relacionado con cualquiera, incluso muy fragmentaria, parte de la cultura tradicional andina poniendo al descubierto lo complejo y multicapa que son sus componentes. "La mosca de la muerte" desvela sus conexiones con los temas que aparecen en la mitología de los pueblos quechua, con el área de sus creencias y él de sus prácticas funerarias, sus conceptos escatológicos, pero también con su folclore y con las metáforas que aparecen en su poesía. No ha sido casual el que la chiririnka se viera reflejada y revivida en la

\footnotetext{
54 LÓPEz BARALT 2012: 25-35.

55 Malocha, Radnicka 2012: 161.

56 Gross 1990: 143-144.

57 CONNOR 2006: 46-47.

58 CONNOR 2006: 36.

59 P. ej.: Gage 2008.
} 
obra de José María Arguedas quien, con su imparable intuición de etnólogo que fue, la inmortalizó en las páginas de la gran literatura peruana que compuso.

\section{BibliografíA}

Arguedas 1981 - J.M. Arguedas, Formación de una cultura nacional indoamericana, selección y prólogo de Á. Rama, México-Madrid-Bogotá: Siglo Veintiuno Editores, 1981.

Arguedas 1977 - J.M. Arguedas, Relatos completos, edición de J. Lafforgue, Buenos Aires: Editorial Losada S.A, 1977.

Arguedas 2001 - J.M. Arguedas, Los ríos profundos, Lima: Editorial Horizonte, 2001.

Arguedas 1964 - J.M. Arguedas, Todas las sangres. Buenos Aires: Editorial Losada 1964.

Arguedas 2011 - J.M. Arguedas, El zorro de arriba y el zorro de abajo, Lima: Editorial Horizonte 2011.

Carranza Romero 2003 - F. Carranza Romero, Diccionario Quechua Ancashino - Castellano, edición y prólogo de W. Lustig, Madrid-Frankfurt am Main: Iberoamericana, Vevuert Verlag 2003.

Carranza Romero 2005 - F. Carranza Romero, El mundo de los muertos en el concepción quechua. Ciberayllu, 12 julio 2005. http://www.andes. missouri.edu/andes/Especiales/FCR_Muertos.html (accedido el 30 de septiembre de 2019).

Cipoletti 1984 - M.S. Cipolleti, El motivo de Orfeo y el viaje al reino de los muertos en América del Sur, "Indiana", vol. 9 (1984), pp. 421-432.

ConNor 2006 - S. Connor, Mucha. Historia - antropologia - kultura, trad. B. Stanek, Kraków: Universitas 2006.

Diccionario 2001 - Diccionario quechua-español Runasimi en línea en Aulex, compilado por P. Jacobs, 2001, http://runasimi.de (accedido el 27 de septiembre de 2016)

Dioses 2012 [1966] - Dioses y hombres de Huarochiri, edición bilingüe, narración quechua recogida por F. de Avila (1598?), trad. J.M. Arguedas, estudio biobibliográfico P. Duviols, Lima: IEP Instituto de Estudios Peruanos 1966 (edición facsimilar 2012).

GAGE 2008 - J. Gage, Kolor i kultura. Teoria i znaczenie koloru od antyku do abstrakcji, trad. J. Holzman, Kraków: Universitas 2008.

GONDOR-WIERCIOCH 2009 - A. Gondor-Wiercioch, Dwa światy, dwie pamięci. Dylemat wielokulturowości w wybranych utworach Louise Erdrich 
i José Marii Arguedasa, Kraków: Wydawnictwo Uniwersytetu Jagiellońskiego 2009.

Gose 2004 - P. Gose, Aquas mortiferas y cerros hambientos: ritos agrarios y formación de clases, Quito: Abya-Yala 2004.

Gross 1990 - R. Gross, Dlaczego czerwień jest barwa miłości. Warszawa: Wydawnictwa Artystyczne i Filmowe 1990.

Guaman Poma de Ayala 1615 - F. Guaman Poma de Ayala, Nueva Crónica y Buen Gobierno, edición electrónica del manuscrito de la Biblioteca Real de Copenhague. http:/www.kb.dk/permalink/2006/poma/283/ es/image/?open=id2686694 (accedido el 20 de septiembre de 2019).

Hocquenghem 1981 - A.M. Hocquenghem, Les mouches et les morts dans l'iconographie Mochica, "Ñawpa Pacha. Journal of Andean Archeology", núm. 19 (1981), pp. 63-67, 69.

Huamán 2004 - C. Huamán, Pachachaka. Puente sobre el mundo. Narrativa, memoria y síbolo en la obra de José María Arguedas, México: El Colegio de México, Centro de Estudios Lingüísticos y Literarios, 2004.

Huchet 2017 - J.-B. Huchet, Des mooches, des morts, des offrandes. Archéoentomologie de tombes mochicas de la pyramide de la Lune, Pérou, "Recherches Amérindiennes au Québec", vol. 47, núms. 2-3 (2017), pp. 23-34.

Inkowie 2015 - Inkowie o Inkach. Antologia, ed. J. Szemiński, Warszawa: Wydział „Artes Liberales”, Uniwersytet Warszawski 2015.

JodŁowska, Mąka 2015 - E. Jodłowska, M. Mąka, La soleded andina del Zorro de Arriba y el Zorro de Abajo, "Estudios Latinoamericanos" vol. 35 (2015), pp. 189-229.

LÉvi-Strauss 1965 - C. Lévi-Strauss, El totemismo en la actualidad, trad. de F. González Aramburo, México: Fondo de la Cultura Económica, 1965. López Baralt 2012 - M. López Baralt, José María Arguedas, poeta y mitógrafo, "América sin Nombre" núm. 17 (2012), pp. 25-35.

MaŁocha, Radnicka 2012 - J. Małocha, K. Radnicka, Symbolika barwy i ksztaltu w religii Azteków, en: J. Marecki, L. Rotter (eds.), Barwy i kształty, (Serie: Symbol - Znak - Przesłanie, vol. 7), Kraków: Uniwersytet Papieski Jana Pawła II w Krakowie, Wydawnictwo Naukowe, 2012, pp. 149-166.

MERINo 2000 - J.M. Merino, La bruja wampiro, en: Leyendas españoles de todos los tiempos, Madrid: Temas de Hoy 2000, pp. 208-209.

MichTA 2013 - L. Michta, Infradźwięki źródtem przeżyć o charakterze religijnym, „Ex Nihilo. Periodyk Młodych Religioznawców”, 2 (10) (2013), pp. 73-92. 
MosZYŃSKi 1967 - K. Moszyński, Kultura ludowa Stowian, vol. 2: Kultura duchowa, parte 1, Warszawa: Książka i Wiedza 1967.

Posern-ZIELIŃSKI 1974 - A. Posern-Zieliński, Ruchy spoteczne i religijne Indian hiszpańskiej Ameryki Poludniowej (XVI-XX w.), Wrocław: Zakład Narodowy im. Ossolińskich 1974.

Ramirez Chacaltana 2014 - J. L. Ramirez Chacaltana, Inticha y Pisacca. http://jurachico.blogspot.com/2014/01/pisacca-perdiz-de-la-puna. html (accedido el 23 de septiembre de 2019).

RYN 2007 - Z.J. Ryn, Medycyna indiańska. Kraków: Wydawnictwo Literackie 2007.

SzEMIŃSKI 1992 - J. Szemiński, El mundo andino dominado por los "muertos rebeldes”, en: M. León-Portilla (ed.), De palabra y obra en el Nuevo Mundo. I. Imágenes Interétnicas, Madrid: Siglo Veintiuno Editores 1992, pp. 171-193.

Szemiński, ZıóŁkowski 2014 - J. Szemiński, M. Ziółkowski, Mity, rytuały i polityka Inków, Warszawa: Państwowy Instytut Wydawniczy 2014.

VAlderrama Fernández, Escalante Gutiérrez 2012 - R. Valderrama Fernández, C. Escalante Gutiérrez, Apu Qorpuna (visión del mundo de los muertos en la Communidad de Awkimarca), en: J.P. Ostrling (ed.), Debates 5 en Antropología, Lima: Pontificia Universidad Católica del Perú 2012, pp. 233-264.

\section{Summary}

\section{The Blue Announcer of Death. From the popular beliefs of the Central An- des}

This essay is a monographic draft attempt concerning one of the most widely known omens of disease and death throughout the native Andean cultures. Among many signs, interpreted as approaching death, the figure of bluebottle fly called in Quechan chiririnka has a key position, which extends from pre-Colombian times, and its popularity exceeds other similar signs of similar meaning. Up to this date, it retains its significance in funerary beliefs and functions in various forms of folklore, especially in songs. At the same time, it is also commonly thought to be an incarnation of human soul, what finds resemblance in folk beliefs and tales of mythic characteristics, including tropes found in indigenous eschatology. This essay relies on ethnographic sources, and very important contributions to this topic, which can be found in books and essays of José María Arguedas.

Keywords: death omens, bluebottle fly, chiririnka, soul, Andean folklore, funerary beliefs, José María Arguedas 


\section{Streszczenie}

\section{Błękitna zwiastunka śmierci. Z wierzeń ludowych środkowych Andów}

Opracowanie jest próbą szkicu monograficznego dotyczącego jednej z najpopularniejszych wróżb choroby i śmierci w tradycyjnych kulturach ludów andyjskich. Wśród wielu znaków interpretowanych jako zapowiedzi zbliżającej się śmierci, postać błękitnej muchy, zwanej w języku keczua chiririnka, należy do szczególnie ważnych, gdyż jej geneza sięga czasów prekolumbijskich, a popularność na terenie Andów przewyższa inne znaki o podobnej treści. Do dziś zajmuje ważne miejsce w wierzeniach funeralnych oraz funkcjonuje w różnych formach folkloru, szczególnie w pieśniach. Równocześnie mucha chiririnka bywa często uważana za inkarnację duszy ludzkiej, co znajduje odzwierciedlenie w ludowych wierzeniach i opowieściach o charakterze mitycznym, zawierających wątki tradycyjnej eschatologii indiańskiej. Opracowanie wykorzystuje źródła etnograficzne oraz bardzo istotne przyczynki do tego tematu zawarte w książkach i opowiadaniach José Marii Arguedasa.

Słowa kluczowe: zapowiedzi śmierci, błękitna mucha, chiririnka, dusza, folklor Andów, wierzenia funeralne, José María Arguedas 